\title{
Research on the development level of science and technology service industry under the information economy
}

\author{
Jinrong Shan ${ }^{1, *}$ \\ ${ }^{1}$ Management Science and engineering,Lanzhou University of Technology,Lanzhou,China
}

\begin{abstract}
ABSRTACT: As a transfer station between economic development and technology, science and technology service industry is an important guarantee for the state to provide services under the strategy of science and technology Innovation. However, in the information age, the development of the industry will be affected by what factors need further in-depth study, this paper based on existing literature, in the original evaluation index system of the development level of science and technology service industry, the information related index is added, and 31 provinces in China are factorial analyzed by using SPSS Statistical Software, and the comprehensive scores of each province and city are calculated and ranked, in order to put forward countermeasures and suggests.
\end{abstract}

\section{Introduction}

The tertiary sector of the economy is a concrete expression of social progress and productivity growth, and its level of development is an important indicator of the country's and region's economic strength and overall competitiveness. The 2013 data show that China's tertiary sector of the economy surpassed the secondary sector of the economy for the first time, the share of GDP is also increasing year by year, and its impact is also increasing year by year. As an important branch of the tertiary sector of the economy, the information technology industry and the science and technology service industry have also been developing rapidly in recent years, and the national and local governments have paid more and more attention to the role of related industries in social and economic development. With the progress of the new generation of information technology, information economy has become the mainstream in the economic society, which has also had a certain impact on the science and technology service industry. It is of great significance to study the development of science and technology service industry in the new information environment.

The research on science and technology service industry has a long history. In foreign research, science and technology service industry is also called knowledge-intensive service industry. This concept was first proposed by Machlup in 1962 in the production and distribution of knowledge in the United States, and classified the science and technology service industry, providing the basis and basis for future research on science and Technology Service Industry. In 1974, Daniel Bell in his research on the impact of technology and science on science and technology services, also proposed the future direction of the development of science and technology services ${ }^{[1]}$. In 2000, Den Hertog pointed out the role of knowledge-intensive services as the bearer of innovation throughout the process ${ }^{[2]}$. On the basis of the definition of industry, scholars also sort out and summarize the classification of science and technology service industry. In 2001, the OECD (Organization for Economic Cooperation and development) emphasized the high technology and labor-intensity input and the high value-added of science and technology service industry, it will use seven categories: information services, market services, financial services, R\&D services, Legal Services, engineering services and management consulting services $^{[3]}$. Howellsc divides knowledge-intensive services into static knowledge services composed of users, platforms, databases and dynamic knowledge services composed of knowledge and users ${ }^{[4]}$. Lee $\mathrm{K}$ $(2003)^{[5]}$ breaks it down into two types of knowledge-intensive services: Enterprise and utility. The United States Department of Commerce will be divided into information services, financial advisory services and other business services.

In view of the measurement of the development level of science and technology service industry, many scholars have given different views. Miles I. (2014) ${ }^{[6]}$ it is proposed that the evaluation system of science and technology service industry includes investment, resources and economic benefits of innovation service. And Shunzhong Liu (2013) ${ }^{[7]}$ has made the further elaboration to the science and technology service industry research, specially has studied the software industry development, the R\&D personnel quantity and R\&D funds, the profit and the patent authorization quantity and so on index take as the key research object.

\footnotetext{
*Corresponding author: 153979652@qq.com
} 
On the other hand, there is no unified concept for the late research on science and technology service industry in Chinese academic circles. In 1992, the National Science and Technology Commission first proposed the composition of science and technology services, including information industry, technology industry and science and technology consulting industry. Diao Wujun $(2015)^{[8]}$ and others evaluated the competitiveness of science and technology service industry from the perspective of economic input-output in terms of development environment, scientific research innovation ability and transformation level of scientific and technological achievements. Hou Ding (2018) ${ }^{[9]}$ evaluated and analyzed the development level of scitech service industry in Shanxi province from four aspects: investment, service capability, service performance and development environment.

\section{Materials and Methods}

In this part, we will use the data of 31 provinces in China to explore the development level of science and technology service industry in the information age.

Firstly, in order to ensure the scientific and rational selection of indicators, this paper, based on the four principles of science, system, representativeness and availability of data, draws on the literature on the evaluation of the development level of science and technology service industry established by relevant scholars, starting from the development scale, input, output and development environment, and adding the relevant indicators that can reflect the informatization, the evaluation indicators of science and technology

Table 1. Index system of development level of science and technology service industry

\begin{tabular}{|c|c|}
\hline Criterion Layer & Index layer \\
\hline $\begin{array}{l}\text { Scale of technology service } \\
\text { industry }\end{array}$ & $\begin{array}{l}\text { Full-time equivalent of R\&D personnel in industrial enterprises above scale } \\
\text { Number of legal person units in science and Technology Service Industry } \\
\text { Number of information-based enterprises } \\
\text { Number of enterprises with e-commerce transactions } \\
\text { Number of urban unit employment in science and technology service industry }\end{array}$ \\
\hline $\begin{array}{l}\text { Investment in science and } \\
\text { technology service industry }\end{array}$ & $\begin{array}{l}\text { Fixed Assets Investment in science and technology service industry } \\
\text { Expenditure on new product development of above scale } \\
\text { Total foreign investment } \\
\text { Government spending on science and technology }\end{array}$ \\
\hline $\begin{array}{l}\text { Outpet in science and } \\
\text { technology service industry }\end{array}$ & $\begin{array}{l}\text { Number of patent applications } \\
\text { Number of patents granted } \\
\text { Turnover of technology market } \\
\text { Revenue from software and information technology services } \\
\text { Sales revenue of new products of industrial enterprises above scale } \\
\text { Number of R\&D projects above scale } \\
\text { Average number of students per } 100,000 \text { persons in institutions of higher } \\
\text { learning } \\
\text { Per capita GDP }\end{array}$ \\
\hline Development environment & $\begin{array}{l}\text { Number of computers per } 100 \text { persons in an enterprise } \\
\text { Internet penetration } \\
\text { Library holdings per capital } \\
\text { Industry average wage }\end{array}$ \\
\hline
\end{tabular}

\section{Results \& Discussion}

According to the steps and methods described in section service industry development are sorted out as shown in Table 1. Among them, the scale of science and technology service industry reflects the overall development level of the industry itself, the input of science and technology service industry represents the core driving force of the development of the industry, and the output of science and technology service industry reflects the development achievements and current situation. The development environment is mainly measured by economic environment, industrial environment, social environment and educational environment.

Secondly, in accordance with the above-mentioned development level indicator system to collect data, data in this paper from the "China Statistical Yearbook 2019”.

Finally, using SPSS20.0 software running data. Due to the large number of evaluation indicators used in this paper and the complicated relationship among the indicators, the factor analysis method can just avoid the error of subjective factors to the results, and at the same time, the correlation among the indicators is taken into account to make the evaluation results more accurate, therefore, this paper uses factor analysis as the evaluation method. The core idea of factor analysis is that after analyzing the internal correlation of the correlation matrix of the original index variables, some variables with complex relations are reduced to a few common factors, which are not related. But before extracting the common factors, we must carry on the necessity test through SPSS statistical software to see whether each index can do the factor analysis.
2, we have quantified the level of science and technology service industry development in 31 provinces of China. Before performing the factor analysis, a correlation test is required, as shown in Table 2. The KMO statistic is 
$0.787>0.5$, and the Bartlett test has a Sig value of $0.000<0.005$, which indicates that the correlation between the indexes is strong, the data are suitable for factor analysis. The comprehensive factor scores and rankings of the provinces are shown in Table 3. Among the top are provinces with high level of economic development and optimized industrial structure, such as Guangdong, Shanghai and Beijing. By the same token, the provinces at the bottom of the list are concentrated in the central and western regions. First of all, the governments of these regions do not give enough support to the science and technology service industry. As a new industry, the development of the science and technology service industry needs the strong support of the government departments in terms of funds and policies. Second, as a knowledge-intensive industry, the development of science and technology service industry can not be separated from a number of high-level professional talent team, in the relevant industry talent resources, the Midwestern Sectional Figure Skating Championships is very inadequate. Moreover, the development environment of Science and technology service industry in the Central and western regions is poor. From the information level, economic development environment and education development environment, we can see that these provinces need to be improved in the development environment. To sum up, the empirical results further show that the development of science and technology service industry is restricted by many factors in the information age, economic Strength, information environment, optimization of industrial structure and talent reserve will influence the development of science and technology service industry in different degree.

Compared with the previous literature, this paper enriches the evaluation system of the development level of science and technology service industry, on the other hand, it pays attention to the influence of informatization on science and technology service industry, joins the relevant index of informatization economy, and follows the trend of the times, it makes more sense to put research into a more realistic context.

Table2. Tests on KMO and Bartlett

\begin{tabular}{|c|c|c|}
\hline \multicolumn{2}{|c|}{ KMO statistics } & 0.787 \\
\hline \multirow{3}{*}{$\begin{array}{c}\text { Bartlett sphericit } \\
\text { y test }\end{array}$} & $\begin{array}{c}\text { Approximate chi-squ } \\
\text { are }\end{array}$ & 1283.112 \\
\cline { 2 - 3 } & df & 210 \\
\cline { 2 - 3 } & Sig & 0.000 \\
\hline
\end{tabular}

Table 3. Comprehensive scores of development by provinces and cities

\begin{tabular}{|c|c|c|c|c|c|}
\hline Province & Combined score & Ranking & Province & Combined score & Ranking \\
\hline Beijing & 0.74 & 5 & Hubei & 0.11 & 9 \\
\hline Tianjin & 0.03 & 11 & Hunan & 0.01 & 12 \\
\hline Hebei & -0.06 & 14 & Guangdong & 2.23 & 1 \\
\hline Shanxi & -0.46 & 22 & Guangxi & -0.39 & 19 \\
\hline Inner Mongolia & -0.52 & 25 & Hainan & -0.64 & 28 \\
\hline Liaoning & -0.24 & 17 & Chongqing & -0.22 & 16 \\
\hline Jilin & -0.42 & 20 & Sichuan & 0 & 13 \\
\hline Heilongjiang & -0.44 & 21 & Guizhou & -0.47 & 23 \\
\hline Shanghai & 0.18 & 6 & Yunnan & -0.47 & 23 \\
\hline Jiangsu & 1.98 & 2 & Tibet & -0.71 & 31 \\
\hline Zhejiang & 1.14 & 3 & Shannxi & -0.17 & 15 \\
\hline Anhui & 0.12 & 8 & Gansu & -0.56 & 27 \\
\hline Fujian & 0.11 & 9 & Qinghai & -0.67 & 30 \\
\hline Jiangxi & -0.26 & 18 & Ningxia & -0.64 & 28 \\
\hline Shandong & 1.08 & 4 & Xinjiang & -0.55 & 26 \\
\hline Henan & 0.14 & 7 & & & \\
\hline
\end{tabular}

investment.

\section{Conclusion}

Based on the results of the factor analysis above, we find that under the information age, the development level of the science and technology service industry in the eastern coastal cities is still higher, while being in the inland and underdeveloped areas, the development of its science and technology service industry is subject to many restrictions. It is worth noting that the level of science and technology service industry in Jiangsu and Zhejiang provinces is higher than that of first-tier cities such as Beijing and Shanghai. This is because these two provinces have seized the opportunity of the times in recent years and vigorously developed the information industry, this has also attracted a large number of high-quality labor force, promoting the progress of various industries. Therefore, based on this, we put forward the following recommendations:

(1) Improve the Government information policy, strengthen the government information industry
Considering from the level of government, it is necessary to speed up and improve the policy guarantee of informatization development. We should standardize the organization and management of the industry, make overall planning for the development of informatization in a scientific and reasonable way, learn and draw lessons from the development experience of the more advanced informatization areas, and formulate policies and systems suitable for our own development path.

(2) Improve the science and technology service industry talent training mechanism, create and develop talent team.

The science and technology service industry has the characteristic of high knowledge and intelligence denseness. To develop the science and technology service industry quickly, we must need high knowledge, high level and high quality talents. It is necessary for the development of science and technology service industry to establish a strong contingent of high-level professionals. 
(3) Improve the science and technology service industry development environment, environmental Protection for development.

In order to develop the science and technology service industry positively and healthily, it is necessary to set up a good development environment, which can not only stimulate the development power, but also improve the achievement and efficiency of the science and technology service industry. Therefore, it is necessary to establish an efficient management system, standardize the statistical standards of science and technology service industry, and further improve the management system of science and technology service industry.

\section{References}

1. Daniel Bell. The coming of post-in dustrial society[M]. New York: American Educational Bookltd, 1974.

2. Den H P. Knowledge-Intensive Business Services as Coproducers of Innovation[J]. International Journal of Innovation Management, 2000, 4(4): 491-528.
3. OECD. Innovation and Productivity in Service[R]. Paris: OECE Report, 2006.

4. Howells J. The nature of innovation in services[R]. Innovation and Productivity in Services, Paris OECD, 2001.

5. Lee K R, Shim S.Knowledge Intensive Service Activities(KISA) in Korea's Innovation System[R]. DECD Report, 2003.

6. Miles I. Services and the Knowledge-Based Economy[J]. World Scientific Book Chapters, 2014(4): 504-518.

7. ShunzhouLiu. innovation Mangement in Knowledge Intensive Business in China[M]. Springer Berlin Herlin Hcidelberg, 2013.

8. Diao Wujun, Hu Wenxiu, Zhang Jianfeng. Study on Evaluation Index System of science and technology service industry -- taking Shaanxi province as an example[J]. Research in science and technology management, 2015, 35(04) : 41-46.

9. Houdin. Evaluation and countermeasures of the development level of science and technology service industry in Shanxi province under the innovation-driven background[D]. Taiyuan University of Technology, 2018. 